\title{
Toward Understanding Posttraumatic Stress and Depression Among Trauma-Affected Widows in Sri Lanka
}

\author{
Jessica E. Lambert \\ California State University, Stanislaus \\ Alyssa Banford Witting \\ Brigham Young University - Provo \\ Spencer James \\ Brigham Young University - Provo, spencer_james@byu.edu \\ Lakmal Ponnamperuma \\ Kaatsu International University \\ Thulitha Wickrama \\ Eqhory thrisansitgdditional works at: https://scholarsarchive.byu.edu/facpub \\ Part of the Other Social and Behavioral Sciences Commons
}

\section{Original Publication Citation \\ Lambert, J. E., Witting, A. B., James, S., Ponnamperuma, L., \& Wickrama, T. (2019). Toward understanding posttraumatic stress and depression among trauma-affected widows in Sri Lanka. Psychological Trauma: Theory, Research, Practice, and Policy, 11(5), 551-558.}

\section{BYU ScholarsArchive Citation}

Lambert, Jessica E.; Witting, Alyssa Banford; James, Spencer; Ponnamperuma, Lakmal; and Wickrama, Thulitha, "Toward Understanding Posttraumatic Stress and Depression Among Trauma-Affected Widows in Sri Lanka" (2018). Faculty Publications. 4048.

https://scholarsarchive.byu.edu/facpub/4048

This Peer-Reviewed Article is brought to you for free and open access by BYU ScholarsArchive. It has been accepted for inclusion in Faculty Publications by an authorized administrator of BYU ScholarsArchive. For more information, please contact ellen_amatangelo@byu.edu. 


\title{
Toward Understanding Posttraumatic Stress and Depression Among Trauma-Affected Widows in Sri Lanka
}

\author{
Jessica E. Lambert \\ California State University, Stanislaus \\ Lakmal Ponnamperuma \\ Kaatsu International University
}

\author{
Alyssa Banford Witting and Spencer James \\ Brigham Young University
}

\author{
Thulitha Wickrama \\ Emory University
}

\begin{abstract}
Objective: In this study, we applied conservation of resources theory (Hobfoll, 1989) to explain high rates of depression and posttraumatic stress symptoms (PTSS) among war- and disaster-affected Tamil widows in the Eastern Province of Sri Lanka. We hypothesized exposure to potentially traumatic events and severity of current contextual problems would influence PTSS and depressive symptoms directly and indirectly through loss of psychological (view of self), environmental (sense of community), and energy (physical health) resources. Method: Trained research assistants interviewed a convenience sample $(N=$ 381) of women, using established measures of the constructs of interest. Data were analyzed using path analysis in MPlus. The significance of the indirect effects was tested using bootstrapping. Results: The model had an acceptable fit $\left(\chi^{2}=4.06, d f=1, p<.05\right.$; Log Likelihood $=-3344.26^{*}$; AIC $=6760.59$; $\mathrm{BIC}=6894.64 ; \mathrm{RMSEA}=0.09 ; \mathrm{CFI}=.99 ; \mathrm{TLI}=.91 ; \mathrm{SRMR}=.02)$ and explained approximately $38 \%$ of the variance in both PTSS and depression. Contextual problems were significantly associated with PTSS and depression both directly and indirectly through deleterious effects on view of self, health status, and sense of community. Degree of trauma exposure was directly associated with indicators of distress. Conclusion: Results support the utility of COR theory in this context and hold implications for research and program development.
\end{abstract}

Clinical Impact Statement

This study evaluated correlates of posttraumatic stress and depression among war- and disasteraffected widowed women in Sri Lanka. Results highlight the importance of examining both exposure to potentially traumatic events and ongoing contextual stressors including economic and social problems. Findings also suggested that negative self-evaluation (e.g., viewing the self as incompetent), sense of community, and health problems were significantly related to psychological distress. Taken together, results of the study highlight the importance of addressing both psychological issues and problematic social conditions in postconflict, low-resource settings.

Keywords: postconflict, widows, COR theory, posttraumatic stress, Sri Lanka

More than two decades of civil war had devastating effects on the people of Sri Lanka. The war, which lasted from 1983 to 2009, was between the Sri Lankan Government and the Liberation Tigers of Tamil Eelam (LTTE), who were attempting to create an inde-

This article was published Online First May 7, 2018.

Jessica E. Lambert, Psychology and Child Development Department, California State University, Stanislaus; Alyssa Banford Witting and Spencer James, School of Family Life, Brigham Young University; Lakmal Ponnamperuma, Department of Psychology, Kaatsu International University; Thulitha Wickrama, Rollins School of Public Health, Emory University.

This research was supported by a Visionary Grant from the American Psychological Foundation.

Correspondence concerning this article should be addressed to Jessica E. Lambert, Psychology and Child Development Department, California State University, Stanislaus, Turlock, CA 95382. E-mail: jlambert@csustan.edu pendent Tamil State in the Northern and Eastern Provinces. The war resulted in at least 100,000 deaths, with many more seriously injured (Siriwardhana \& Wickramage, 2014). Over one million people were displaced internally or externally because of the conflict. Although most have returned, as of 2016, approximately 44,000 people are still internally displaced (International Displacement Monitoring Centre, n.d.a). The warfare was brutal, particularly in the final months of the war when tens of thousands of Tamil civilians were allegedly killed (United Nations, 2011). According to the International Crisis Group (2010), both sides committed violations of international humanitarian law including shelling of civilians, hospitals, and humanitarian organizations. Civilians and families were harmed both directly through war exposure and indirectly through the impacts of war on the culture and economy (Herath, 2012). Ongoing political tensions have impeded recovery (International Crisis Group, 2010). 
The 2004 Indian Ocean tsunami further depleted the already limited resources of those affected by the war. There were approximately 30,000 deaths throughout the country (Nishikiori et al., 2006), and 515,000 individuals experience prolonged displacement (International Displacement Monitoring Centre, n.d.a). Smaller natural disasters, primarily floods and storms, have affected the country since 2004, with hundreds of thousands displaced by disasters each year (International Displacement Monitoring Centre, n.d.b).

There have been substantial demographic changes in Sri Lanka from war- and disaster-related deaths, prolonged displacement, and migration. The most notable change is the increase in femaleheaded households in the Eastern and Northern Provinces (Silva, 2012). The civil war resulted in an estimated 89,000 widows in Sri Lanka, with 49,000 living in the Eastern Province, the majority of whom are Tamils (Sajanthan, Rasnayake, Kamalrathne, Chamikara, \& Gnanaratne, 2014). Households headed by widowed Tamil women have several vulnerabilities including poverty and discrimination (Jayawickreme, Jayawickreme, \& Miller, 2010; Silva, Sivakanthan, \& Wickramasinghe, 2012). Stigma toward widows is prevalent (Rajasingham-Senanayake, 2004; Tribe \& De Silva, 1999). Although scant, existing studies of widows in Sri Lanka have documented a general sense of fear, insecurity, and unease in daily life (Silva, 2012). High rates of anxiety and depression have been documented among samples of war-affected Tamil women (Husain et al., 2011; Siriwardhana et al., 2013). In a large crosssectional study of war-affected Tamils in the Northern Province, for example, women were more likely than men to report clinically significant symptoms of anxiety and depression (Husain et al., 2011). Furthermore, Siriwardhana et al. (2013) found that being a widow or divorced woman was predictive of somatic symptoms, depression, and anxiety. In this study, we aimed to better understand correlates of psychological distress among war and disaster affected widows.

According to conservation of resources theory (COR; Hobfoll, 1989), cumulative trauma has an impact on individuals through loss of vital material, environmental (e.g., livelihood, relationships), psychological (e.g., self-efficacy, hope), and energy (e.g., physical health, income) resources. The loss of resources can have a cascading effect, whereby the loss of one resource leads to other resource loss, which in turn can cause a compounding of psychological responses (Hobfoll, 1991). The existence of many resources is dependent on the coexistence of other resources as well as an infrastructure for them to function within (Hobfoll, 2011). In Sri Lanka, for example, the civil war and tsunami both had impacts on the economy and employment opportunities, safety of buildings and roads, and the medical infrastructure. Losses such as these result in stressful living conditions (i.e., contextual stressors) that likely interfere with the recovery process following exposure to potentially traumatic events (PTEs). Contextual stressors including insufficient access to basic needs, limited economic opportunities, and social unrest may be more detrimental to well-being than the actual exposure to PTEs (Miller \& Rasmussen, 2010, 2014).

In addition to PTEs and contextual problems, we were interested in variables that may explain associations between exposure to PTEs, contextual problems and psychological distress. Drawing from COR theory (Hobfoll, 1989) and our previous work with this population (Lambert, Witting, Anderson, Ponnamperuma, \& Wickrama, 2017), we evaluated three potential mediators that represented psychological (one's view of their own competence and worth), environmental (sense of connection to community), and energy (physical health) resources.

On an individual level, exposure to trauma is associated with reduced psychological resources including self-efficacy and hope (Hobfoll, Canetti-Nisim, \& Johnson, 2006). Negative beliefs are believed to contribute to the development and maintenance of symptoms following trauma (Ehlers \& Clark, 2000; Foa, Huppert, \& Cahill, 2006). There is a large body of research demonstrating associations between posttraumatic cognitions (PTCs) and posttraumatic stress (PTSS) among diverse populations of traumaexposed individuals, and alterations in cognitions are now part of the PTSD diagnosis in the Diagnostic and Statistical Manual of Mental Disorders (DSM-5; American Psychiatric Association, 2013). Several studies have also demonstrated that changes in cognitions over the course of therapy are associated with reductions in PTSS (McLean, Yeh, Rosenfield, \& Foa, 2015; Schumm, Dickstein, Walter, Owens, \& Chard, 2015).

Negative self-evaluation, a primary type of PTC, is also predictive of depressive symptoms among samples of trauma-exposed populations. For example, in a longitudinal study of survivors of motor vehicle accidents, negative trauma-related cognitions were associated with both PTSS and depression six months following the first evaluation (Ehring, Ehlers, \& Glucksman, 2008). In our previous work on widowed women in Sri Lanka (Lambert et al., 2017), we found that participants who experienced ongoing warrelated problems reported more negative self-evaluations and more severe symptoms of depression. Given this finding and the literature on salience of negative cognitions in psychological distress, we hypothesized that PTCs would help explain the associations between exposure to traumatic events and ongoing contextual stressors and indicators of psychological distress.

Civil war results in a breakdown of social networks because of group conflicts that continue even after the war ends (Colletta \& Cullen, 2000). Community divisions potentially lead to tensions and discrimination, thereby impeding recovery (Betancourt, Agnew-Blais, Gilman, Williams, \& Ellis, 2010). In Sri Lanka, social networks within villages that have traditionally been an integral part of daily life and an important source of support have in many cases been shattered (Herath, 2012; Somasundaram, 2007). These changes have altered the social fabric of communities in the Eastern Province. Without these social and economic resources, an individual's ability to recover from the stress of the trauma may be compromised (Hobfoll, 2014). In this study, we proposed that a compromised sense of community connection would help explain the association between exposure to trauma and stressors and psychological distress.

Physical illness and other health problems are common in areas affected by war, particularly among those who are displaced (Leaning \& Guha-Sapir, 2013; Murray, King, Lopez, Tomijima, \& Krug, 2002; Nagai, Abraham, Okamoto, Kita, \& Aoyama, 2007). Protracted conflict tends to increase existing health disparities (Roberts, Patel, \& McKee, 2012). Health problems result from direct exposure to conflict (e.g., bombings, landmines), and the decrease in quality and availability of health care, lack of food and clean water, and increased spread of diseases (Leaning \& GuhaSapir, 2013, Murray et al., 2002). The effects on public health and the health care systems can last years beyond the end of the 
conflict; women and children are typically the most affected (Ghobarah, Huth, \& Russett, 2004).

Health problems among war-affected communities in Sri Lanka have been well-documented (Siriwardhana \& Wickramage, 2014). During the war, there were increased rates of maternal and infant mortality in the Northern Province (Kottegoda, Samuel, \& Emmanuel, 2008; Reilley, Simpson, Ford, \& Dubois, 2002; Simetka, Reilley, Joseph, Collie, \& Leidinger, 2002), as well as increased spread of infectious diseases (Dahanayaka, Kiyohara, \& Agampodi, 2013). Furthermore, years of ongoing economic and social problems created stressful conditions for much of the population in the Eastern Provinces. Both PTEs (López-Martínez et al., 2016) and chronic stress (Juster, McEwen, \& Lupien, 2010) are associated with health problems among culturally diverse populations. We proposed that PTEs and contextual stressors would be associated with a poorer health status, which in turn would be associated with more severe PTSS and depression.

\section{Present Study}

In this study, we attempted to explain variation in PTSS and depression among disaster-affected Tamil widows in Eastern Sri Lanka with a model based on COR theory and previous research. We hypothesized that greater exposure to traumatic events and more contextual problems would be associated with higher levels of depression and PTSS. We also sought to determine if PTCs about the self, sense of community, and physical health status would explain variation in depression and PTSS. We hypothesized that a more negative view of self and poorer heath would be associated with higher symptoms, whereas a stronger sense of community would be associated with lower symptoms. Lastly, we predicted that exposure to PTEs and contextual problems would be associated with indicators of psychological distress (PTSS and depression) directly and indirectly through PTCs, sense of community, and health status.

\section{Method}

\section{Participants}

Participants were 381 war- and disaster-affected Tamil widows living in Eastern Sri Lanka. The age of the sample ranged from 19 to 86 , with a median age of $56(M=55.25, S D=12.23)$. Approximately one third of the women were employed outside the home, primarily in labor-type work including working in rice paddies or other farming jobs, cleaning, and cooking. The median income in the last year was 50,000 Sri Lankan Rupees ( 341 U.S. dollars).

The most common cause of death of the participants' husbands was health problems $(51.9 \%)$, followed by war-related violence $(25.2 \%)$. Other identified causes included accidents (5.5\%), unresolved disappearance $(5.2 \%)$, the 2004 tsunami (4.9\%), suicide $(3.6 \%)$, and murder $(1 \%)$. The length of time since the husband's death ranged from less than 1 year to 61 years $(M=14.27, S D=$ 9.75). Most women were currently living with the immediate or extended family. On average women had four children and lived with at least four other people.

Participants were exposed to approximately seven PTEs on average; $85 \%$ had been internally displaced at some point, $51 \%$ had loved ones killed in the war, and $44 \%$ experienced a serious trauma related to the 2004 tsunami. On the posttraumatic symptom scale of the Harvard Trauma Questionnaire (Mollica et al., 1992), $32 \%$ of the sample had clinically significant symptoms $(>2.5)$. On the Hopkins symptom checklist (Derogatis, Lipman, Rickels, Uhlenhuth, \& Covi, 1974), over $80 \%$ of the sample had depression scores above the clinical cutoff of 1.75 .

\section{Measures}

Harvard Trauma Questionnaire (HTQ; Mollica et al., 1992). The original HTQ has four parts: a checklist of potentially traumatic events, a section for respondents to describe their most distressing experience, a screening for head injuries, and items assessing posttraumatic stress symptoms on a scale ranging from 1 (not at all) to 4 (extremely). There is also an appendix for assessing exposure to torture. The number of items on the checklist of traumatic events and the symptom checklist vary on different versions of the HTQ because each is adapted to fit the local context. The measure is intended to be administered in an interview format.

Husain et al. (2011) translated into Tamil the checklist of traumatic events and 17 items that assess posttraumatic stress symptoms based on $D S M-I V$ criteria. The authors validated the measure with a sample of war-affected Tamil Sri Lankans $(N=$ 1409). The checklist includes DSM criteria A events (e.g., injury from gunshots, exposure to bombing) and events common in war-affected contexts that have been shown to be correlated with distress (e.g., being forced to live in an internal displacement camp). Husain et al. included 20 items assessing trauma exposure; three of these (rape, imprisonment, torture) were not included in this study because it was determined that answering such questions could put participants at risk given the political context. Participants were asked if they experienced each of the 17 PTEs and responded with yes or no. We summed the number of events as an indicator of trauma exposure. Items on the posttrauamtic symptom scale are rated on a scale ranging from 1 (not at all) to 4 (extremely). The scale is scored by computing the average score of items; scores $>2.5$ are considered clinically significant. Cronbach's alpha for the present sample was .87 .

Hopkins Symptom Checklist-Depression Scale (HSCL-25; Derogatis et al., 1974). The HSCL depression scale was translated into Tamil and validated by Husain et al. (2011). The depression scale consists of 15 items assessing symptoms of depression (e.g., low energy, sleep disturbance, worthlessness) on a scale ranging from 1 (not at all) to 4 (extremely). An average score is calculated; scores $>1.76$ are considered clinically significant. Cronbach's alpha for this sample was .79.

Penn/RESIST/Peradeniya War Problems Questionnaire (PRPWPQ; N. Jayawickreme, Jayawickreme, Goonasekera, \& Foa, 2009). The PRPWPQ was developed from qualitative interviews with 604 war-affected Tamil women and men living in the Eastern and Northern Provinces in Sri Lanka. The authors developed a measure that assesses trauma exposure (torture and other war trauma), contextual problems (economic, lack of basic needs, family problems, social problems, physical problems), and psychological distress (depression, anxiety, other symptoms). Based on our pilot work, we used three subscales from the PRPWPQ to assess problems with basic needs, social problems, and economic 
problems with a total of 32 items. Participants were asked if they experienced specific problems (yes/no). The basic needs subscale was composed of 8 items, including lack of food, lack of clean water, lack of fuel, and lack of safety due to being a widow. Economic problems were assessed with 10 items including lack of money, lack of employment opportunities, and loss of land/home. Social problems were assessed with 14 items including living alone, stress of moving to a new place, lack of respect from society, and fear of sexual attacks due to being a widow. We created a total scale by tallying the number of yes responses to all items. Higher scores indicate more stressors. The alpha for this scale was not available from previous studies; Cronbach's alpha in this study was .84 .

Sense of Community Index (SCI; Perkins, Florin, Rich, Wandersman, \& Chavis, 1990). The SCI is a 12-item scale designed to assess four domains of psychological sense of community: membership, emotional connection to others, needs fulfillment, and perceived influence. Although originally proposed to have a four-factor structure, more recent studies have found a single-factor scale to offer a better fit (Long \& Perkens, 2003). The measure has been translated into Spanish, French, and Portuguese and has been used with culturally diverse populations across the U.S. For the present study, we had the measure translated into Tamil by a professional translation company. The measure was then back-translated and corrected by bilingual members of our research team. Researchers have used variations on the reference group including "neighborhood," "block," and "college." In this study, we used "village" to reflect the local terminology. Example items included "People in this village share the same values," "I feel at home in this village," and "The people in this village get along well." Participants responded to items on a Likert scale ranging from 1 (strongly disagree) to 5 (strongly agree). Scores were calculated by taking the average of participant responses; higher scores indicated a stronger sense of community. Cronbach's alpha for the scale was $\alpha=.84$.

Posttraumatic Cognitions Inventory (PTCI; Foa et al., 1999). The PTCI is a 33 -item measure that assesses maladaptive beliefs following trauma on three subscales: (1) negative cognitions about the self, (2) negative cognitions about others and the world, and (3) self-blame. The measure was translated and backtranslated by two Tamil-speaking academics and piloted in a previous study (Lambert et al., 2017). Only the cognitions-aboutself subscale had acceptable psychometric properties in our pilot data. Thus, only this subscale was used in the present study. This 21-item subscale is composed of items assessing beliefs about the self, including "I can't trust that I will do the right thing" and "I can't deal with even the slightest upset." Items are rated on a Likert scale ranging from 1 (totally disagree) to 7 (totally agree). Scores were calculated by taking the average of participant responses; higher scores indicated more negative cognitions about the self. Cronbach's alpha for the current study was .78.

Subjective health rating. Two items that are commonly used in epidemiological studies of health were used as an indicator of health status (Eriksson, Undén, \& Eloffsson, 2001). These items are robust predictors of mortality and correlate with a range of health problems. The items "In general how would you rate your health?" and "How would you assess your general health status compared to others your own age" were rated on a scale ranging from 1 (very good) to 5 (very bad). Ratings for the two items were averaged. Higher scores mean the person has relatively more health problems. Cronbach's alpha in this study was .77.

\section{Procedures}

The Institutional Review Board at California State University, Stanislaus approved all study procedures prior to data collection. We gathered data over the course of three weeks in four divisions (two coastal and two inland) in the Eastern Province. Our local collaborators advertised the study by word of mouth. On the prescribed dates, our research team met women at village community centers. Trained bilingual research assistants ( 3 women and 2 men) collected data in an interview format, and recorded respondents' answers to survey questions on tablets using QuickTap Survey software. The interviews lasted approximately $90 \mathrm{~min}$ each. The majority of women who came to the community centers during data collection were interviewed. However, exact participation rate was not recorded. Participants were incentivized with approximately \$5 USD worth of food and commonly purchased goods.

\section{Data Analysis}

Data were collected from 400 women; due to an error with one of the tablets, data were lost from approximately 15 women. Four women with missing data on one or more measures were omitted from the sample. Among the sample of 381 women, there were a few cases with data missing at the item level; mean scores were calculated using available data. This approach has been shown to be equivalent to multiple imputation (Parent, 2013). The path model was fit in MPlus (Muthén \& Muthén, 1998-2017) using maximum likelihood estimation. This allowed us to assess the direct effects of our proposed independent variables (contextual stressors and trauma exposure) on our dependent variables (PTSS and depression), as well as indirect effects through proposed mediators (sense of community, PTC, health status). The significance of the indirect effects was tested using bootstrapping.

\section{Results}

Means, standard deviations, and bivariate correlations between variables are shown in Table 1 . The path model fit was adequate $\left(\chi^{2}=4.06, d f=1, p<.05 ; \log\right.$ Likelihood $=-3344.26^{*} ;$ AIC $=$ $6760.59 ; \mathrm{BIC}=6894.64 ; \mathrm{RMSEA}=0.09 ; \mathrm{CFI}=.99 ; \mathrm{TLI}=.91 ;$ SRMR $=.02$ ). Unstandardized path coefficients are shown in Figure 1. PTE and contextual problems explained 5\% of the variance in PTC, $8 \%$ of the variance in sense of community, and $10 \%$ of the variance in health problems. The model explained approximately $38 \%$ of the variance in both PTSS and depression.

All direct paths were statistically significant except for the association between the PTE and health problems. Most associations were in the hypothesized direction, with two exceptions. First, although the bivariate correlation between PTE and PTC was nonsignificant, once entered in the model, the path between these two variables was statistically significant and negative, suggesting that a higher number of PTEs was associated with fewer PTCs about the self. Second, the association between PTEs and sense of community again suggested that greater trauma exposure was associated with a stronger sense of community. As shown in Figure 1, other associations were in the expected direction. 
Table 1

Descriptive Statistics and Intercorrelations Among Study Variables

\begin{tabular}{lrrrrrrrrr}
\hline \multicolumn{1}{c}{ Variable } & Mean & $S D$ & 1 & 2 & 3 & 4 & 5 & 6 & 7 \\
\hline 1. PTE & 7.32 & 2.92 & - & $.27^{* * *}$ & -.05 & $.15^{* * *}$ & .07 & $.14^{* * *}$ & $.15^{* * *}$ \\
2. Context & 14.83 & 6.13 & & - & $.21^{* *}$ & $-.19^{* *}$ & $.32^{* * *}$ & $.44^{* * *}$ & $.48^{* * * *}$ \\
3. PTC & 3.91 & 1.33 & & & - & $.17^{* *}$ & -.03 & $.24^{* *}$ & $.16^{* * *}$ \\
4. Community & 3.99 & .59 & & & & - & $-.15^{* * *}$ & $-.34^{* *}$ & $-.37^{* * *}$ \\
5. Health & 2.92 & .91 & & & & & - & $.30^{* *}$ & $.29^{* * *}$ \\
6. Depression & 2.39 & .50 & & & & & & - & $.77^{* * *}$ \\
7. PTSS & 2.21 & .57 & & & & & & & - \\
\hline
\end{tabular}

Note. $\quad N=381$. PTE $=$ Number of potentially traumatic events reported; Context $=$ Sum of war-related contextual problems; PTC = Mean score on the self-subscale of the Posttraumatic Cognitions Inventory; Community $=$ Sense of Community Index average score; Health $=$ Average rating of health problems; Depression $=$ Depression symptoms; PTSS $=$ Posttraumatic stress symptoms.

**** $p<.01$.

We examined 12 indirect paths examined in the model (see Table 2). Four paths each were fit to assess the indirect associations between the independent and dependent variables through PTC, sense of community, and perceived health. Of the 12 paths, three were nonsignificant. Direct paths from PTE to PTSS and depression were positive, as expected; however, the three significant indirect paths from PTE to PTSS and depression through PTC and sense of community were negative. This occurred because associations between PTE to PTC and sense of community were in the opposite direction than predicted. In the case of PTC, which had a near zero bivariate correlation with PTE, contextual problems could be functioning as a suppressor variable. It is also important to note that we omitted rape and torture from the PTE checklist, which could account for the unexpected finding.

Indirect paths from contextual problems to PTSS and depression through PTC, sense of community, and health problems were significant and in the expected direction. Higher contextual prob- lems were associated with more negative PTCs about the self, a weaker sense of community, and more health problems. These variables, in turn, were associated with higher PTSS and depression. Results are consistent with partial mediation.

\section{Discussion}

In this study, we hypothesized that exposure to PTEs and contextual problems would explain variability in PTSS and depression directly and indirectly through associations with PTCs about the self, sense of community, and health status. Our hypotheses regarding contextual problems were supported. Findings regarding associations between PTEs and our proposed mediating variables were more complex.

Research has shown a dose-response association between exposure to war-related PTEs and psychosocial problems (Johnson \& Thompson, 2008). Associations between PTEs and indicators of

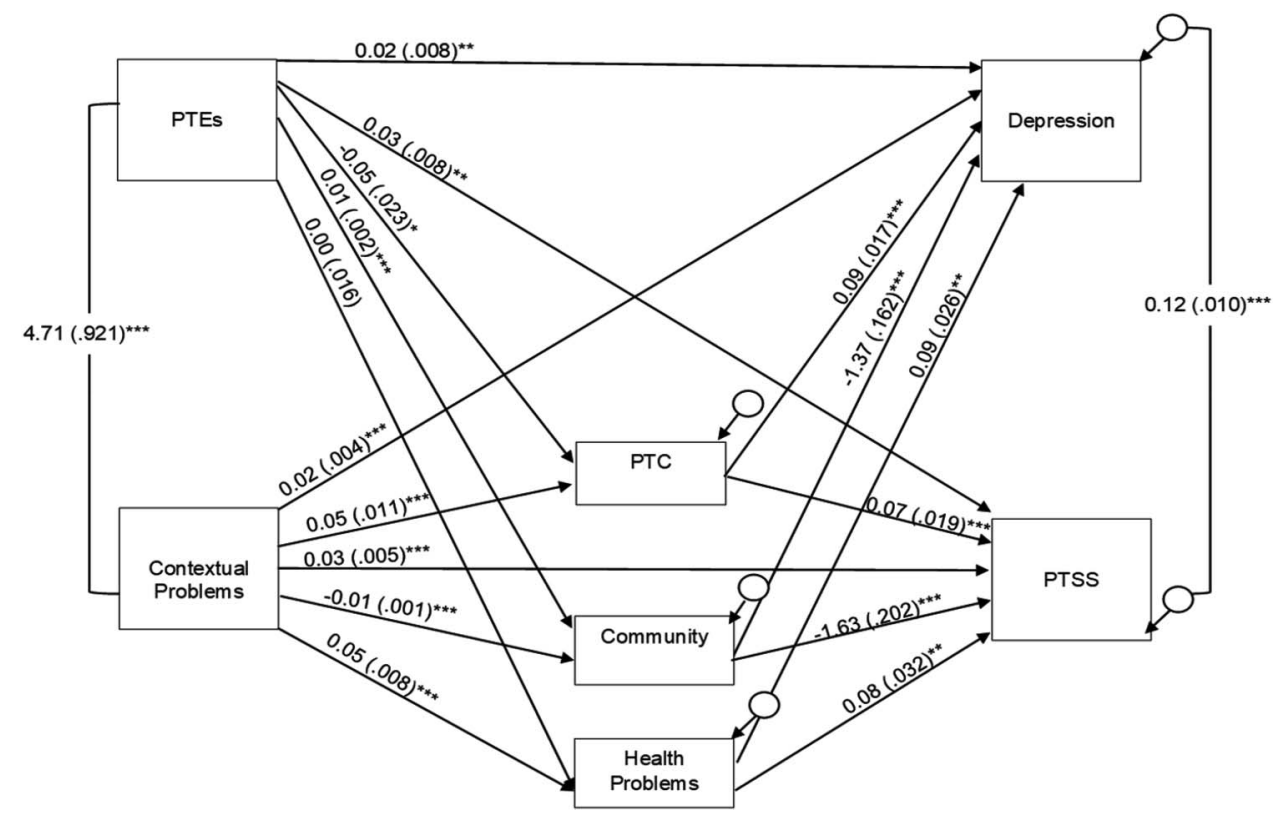

Figure 1. Path model depicting hypothesized associations between study variables. Unstandardized regression weights with standard errors in parentheses are shown. ${ }^{*} p<.05 .{ }^{* *} p<.01$. $^{* * *} p<.001$. 
Table 2

Indirect Effects for 12 Paths

\begin{tabular}{lcccc}
\hline \multicolumn{1}{c}{ Path } & $\begin{array}{c}\text { Indirect } \\
\text { effect }\end{array}$ & SE & $95 \%$ CI & $p$-value \\
\hline PTE $\rightarrow$ PTC $\rightarrow$ Depression & -.005 & .002 & {$[-.009,-.001]$} & .049 \\
PTE $\rightarrow$ PTC $\rightarrow$ PTSS & -.003 & .002 & {$[-.007,-.001]$} & .062 \\
PTE $\rightarrow$ Community $\rightarrow$ Depression & -.014 & .003 & {$[-.020,-.009]$} & .000 \\
PTE $\rightarrow$ Community $\rightarrow$ PTSS & -.016 & .004 & {$[-.024,-.011]$} & .000 \\
PTE $\rightarrow$ Health $\rightarrow$ Depression & .000 & .001 & {$[-.003, .002]$} & .840 \\
PTE $\rightarrow$ Health $\rightarrow$ PTSS & .000 & .001 & {$[-.003, .002]$} & .844 \\
Context $\rightarrow$ PTC $\rightarrow$ Depression & .005 & .001 & {$[.003, .007]$} & .001 \\
Context $\rightarrow$ PTC $\rightarrow$ PTSS & .003 & .001 & {$[.002, .006]$} & .008 \\
Context $\rightarrow$ Community $\rightarrow$ Depression & .007 & .002 & {$[.004, .010]$} & .000 \\
Context $\rightarrow$ Community $\rightarrow$ PTSS & .008 & .002 & {$[.005, .012]$} & .000 \\
Context $\rightarrow$ Health $\rightarrow$ Depression & .004 & .001 & {$[.002, .007]$} & .002 \\
Context $\rightarrow$ Health $\rightarrow$ PTSS & .004 & .002 & {$[.002, .007]$} & .014 \\
\hline
\end{tabular}

Note. $\quad$ PTE $=$ Number of potentially traumatic events reported; Context $=$ Contextual problems; $\mathrm{PTC}=$ Mean score on the self-subscale of the Posttraumatic Cognitions Inventory; Community = Sense of Community Index average score; Health $=$ Average rating of health problems; Depression $=$ Depression symptoms; PTSS $=$ Posttraumatic stress symptoms.

psychological distress in our study are consistent with this finding; however, contrary to our hypotheses, results suggested that greater trauma exposure was associated with fewer negative beliefs about the self and a stronger sense of community. The association with health status was nonsignificant. It is important to note when interpreting this finding that torture and sexual assault, the two types of traumatic events that are known to be most strongly associated with problematic outcomes for survivors, were not assessed, which likely affected results. Another interpretation is that there is a more complex relation among these variables than was included in this model. It is possible, for example, that some unmeasured variable moderates the association been PTEs, sense of community, and PTCs.

Our results suggest that systemic economic and social problems caused or amplified by war and disaster were relatively more important than exposure to the PTEs assessed in this study. This is consistent with COR theory as well as an ecological model of the impacts of conflict on civilians (Miller \& Rasmussen, 2017). Although PTEs are important to consider, among this sample most events measured on the checklist had occurred prior to 2009. In contrast, contextual stressors (e.g., lack of money, no access to health care, lack of security) were ongoing. Recent studies have demonstrated the relative importance of similar stressors among populations affected by mass trauma (Miller \& Rasmussen, 2010, 2014). Furthermore, research has shown the deleterious effects of chronic environmental stress on psychological and physical health among diverse populations (see Juster et al., 2010 for a review).

We found evidence of a cascading effect (Hobfoll, 1991) in that contextual problems were associated with lowered psychological, environmental, and energy resources. First, women who reported more contextual stressors also endorsed more negative PTCs about the self. It may be that stressful life circumstances have contributed to a loss of self-efficacy. In our previous research with this population (Witting, Lambert, \& Wickrama, 2016), widows who reported higher war-related problems and disaster-related losses also reported lower efficacy in their ability to care for their family.

Increased contextual problems were also associated with lower perceived sense of community. From a COR perspective, this could represent a decline in social resources related to ongoing war-related problems. Our results are in line with findings from a qualitative study of war-affected Tamils that suggested the war had lasting effects on the social function of communities (Somasundaram, 2007). The importance of social relationships for mental health has been demonstrated cross-culturally. Sense of community may be particularly salient in the cultural context of Sri Lanka, where the village has typically been central to daily life and well-being (Somasundaram, 2007).

Regarding the association between contextual problems and health, it is possible the stress from chronic social and economic problems had a negative impact on physical health (Juster et al., 2010). Adversity and marginalization has been shown to have a weathering effect on the health of minorities is the U.S., where the physiological effects of stress erode health over time (Geronimus, Hicken, Keene, \& Bound, 2006). Limited access to health care during and after the war also likely played a role.

Several limitations of the study must be considered. It is important to note data were collected at one point in time; as such, we cannot draw causal conclusions from the data, or be certain of the direction of the associations. A second limitation is the use of psychological measures that were developed within a Western context. The utility of PTSD for trauma-affected populations in international settings has been a source of debate for years; however, there is a growing amount of evidence for the cross-cultural validity of this diagnosis (Hinton \& Lewis-Fernández, 2011). To our knowledge, the Sense of Community Index has not previously been used in this context. Given the collective culture and importance of village life for this population, we argue that the construct itself is relevant. However, it should be noted that a measure of this construct, and indeed all the constructs assessed in this study, that was developed within the cultural context may better reflect participants' experiences.

The exclusion of items assessing rape, torture, and imprisonment is an additional limitation. Given the ongoing political tensions surrounding alleged war crimes (International Crisis Group, 2010), we opted to exclude these items because disclosure could potentially put participants at risk. Data were collected via inter- 
views; thus, the possibility of social desirability needs to be considered.

Regarding future research, longitudinal studies would shed light on how women and communities change following war and disaster. Longitudinal research might investigate the possible protective role of a strong sense of community following exposure to trauma. Treatment research is warranted given the high percentage of women with elevated symptoms of PTSS and depression. Our results suggest an integrative approach that addresses problematic social conditions, health issues, and psychological distress should be considered. There is emerging evidence for the utility of combining psychosocial and economic development to address both mental health problems and livelihoods among populations in postconflict settings (Kumar \& Willman, 2016). Regarding psychological interventions, our results demonstrate the salience of PTCs and sense of community; thus, treatments that address problematic thinking patterns and help foster social connection may be beneficial in reducing symptoms.

\section{References}

American Psychiatric Association. (2013). Diagnostic and statistical manual of mental disorders (5th ed.). Washington, DC: Author.

Betancourt, T. S., Agnew-Blais, J., Gilman, S. E., Williams, D. R., \& Ellis, B. H. (2010). Past horrors, present struggles: The role of stigma in the association between war experiences and psychosocial adjustment among former child soldiers in Sierra Leone. Social Science \& Medicine, 70, 17-26. http://dx.doi.org/10.1016/j.socscimed.2009.09.038

Colletta, N. J., \& Cullen, M. L. (2000). Violent conflict and the transformation of social capital: Lessons from Cambodia, Rwanda, Guatemala, and Somalia. Washington, DC: The World Bank.

Dahanayaka, N. J., Kiyohara, T., \& Agampodi, S. B. (2013). Massive hepatitis A outbreak in Sri Lanka in 2009: An indication of increasing susceptibility and epidemiological shift? Sri Lankan Journal of Infectious Diseases, 3, 28-30. http://dx.doi.org/10.4038/sljid.v3i2.5640

Derogatis, L. R., Lipman, R. S., Rickels, K., Uhlenhuth, E. H., \& Covi, L. (1974). The Hopkins Symptom Checklist (HSCL): A self-report symptom inventory. Systems Research and Behavioral Science, 19, 1-15. http://dx.doi.org/10.1002/bs.3830190102

Ehlers, A., \& Clark, D. M. (2000). A cognitive model of posttraumatic stress disorder. Behaviour Research and Therapy, 38, 319-345. http:// dx.doi.org/10.1016/S0005-7967(99)00123-0

Ehring, T., Ehlers, A., \& Glucksman, E. (2008). Do cognitive models help in predicting the severity of posttraumatic stress disorder, phobia, and depression after motor vehicle accidents? A prospective longitudinal study. Journal of Consulting and Clinical Psychology, 76, 219-230. http://dx.doi.org/10.1037/0022-006X.76.2.219

Eriksson, I., Undén, A. L., \& Elofsson, S. (2001). Self-rated health. Comparisons between three different measures. Results from a population study. International Journal of Epidemiology, 30, 326-333. http:// dx.doi.org/10.1093/ije/30.2.326

Foa, E. B., Ehlers, A., Clark, D. M., Tolin, D. F., \& Orsillo, S. M. (1999). The Posttraumatic Cognitions Inventory (PTCI): Development and validation. Psychological Assessment, 11, 303-314. http://dx.doi.org/10 .1037//1040-3590.11.3.303

Foa, E. B., Huppert, J. D., \& Cahill, S. P. (2006). Emotional processing theory: An update. In B. O. Rothbaum (Ed.), Pathological anxiety: Emotional processing in etiology and treatment (pp. 3-24). New York, NY: Guilford Press.

Geronimus, A. T., Hicken, M., Keene, D., \& Bound, J. (2006). "Weathering" and age patterns of allostatic load scores among Blacks and Whites in the United States. American Journal of Public Health, 96, 826-833. http://dx.doi.org/10.2105/AJPH.2004.060749
Ghobarah, H. A., Huth, P., \& Russett, B. (2004). The post-war public health effects of civil conflict. Social Science \& Medicine, 59, 869-884. http://dx.doi.org/10.1016/j.socscimed.2003.11.043

Herath, D. (2012). Wounded society: Social wounds of the war and the breakup of community social structures in Northern Sri Lanka. In D. Herath \& K. T. Silva (Eds.), Healing the wounds: Rebuilding Sri Lanka after the war (pp. 58-95). Colombo, Sri Lanka: International Center for Ethnic Studies.

Hinton, D. E., \& Lewis-Fernández, R. (2011). The cross-cultural validity of posttraumatic stress disorder: Implications for DSM-5. Depression and Anxiety, 28, 783-801. http://dx.doi.org/10.1002/da.20753

Hobfoll, S. E. (1989). Conservation of resources. A new attempt at conceptualizing stress. American Psychologist, 44, 513-524. http://dx.doi .org/10.1037/0003-066X.44.3.513

Hobfoll, S. E. (1991). Traumatic stress: A theory based on rapid loss of resources. Anxiety Research, 4, 187-197.

Hobfoll, S. E. (2011). Conservation of resources theory: Its implication for stress, health, and reliance. In S. Folkman (Ed.), The Oxford handbook of stress, health, and coping (pp. 127-147). New York, NY: Oxford University Press.

Hobfoll, S. (2014). Resource caravans and resource caravan passageways: A new paradigm for trauma responding. Intervention, 12, 21-32. http:// dx.doi.org/10.1097/WTF.0000000000000067

Hobfoll, S. E., Canetti-Nisim, D., \& Johnson, R. J. (2006). Exposure to terrorism, stress-related mental health symptoms, and defensive coping among Jews and Arabs in Israel. Journal of Consulting and Clinical Psychology, 74, 207-218. http://dx.doi.org/10.1037/0022-006X.74.2 207

Husain, F., Anderson, M., Lopes Cardozo, B., Becknell, K., Blanton, C., Araki, D., \& Kottegoda Vithana, E. (2011). Prevalence of war-related mental health conditions and association with displacement status in postwar Jaffna District, Sri Lanka. Journal of the American Medical Association, 306, 522-531. http://dx.doi.org/10.1001/jama.2011.1052

International Crisis Group. (2010). War crimes in Sri Lanka. Retrieved from https://www.crisisgroup.org/asia/south-asia/sri-lanka/war-crimessri-lanka

International Displacement Monitoring Centre. (n.d.a). Country profile: Sri Lanka. Retrieved from: http://www.internal-displacement.org/countries/ sri-lanka

International Displacement Monitoring Centre. (n.d.b). Global report on internal displacement. Retrieved from: http://www.internal-displacement .org/global-report/grid2017/

Jayawickreme, E., Jayawickreme, N., \& Miller, E. (2010). Triumphalism, fear and humiliation: The psychological legacy of Sri Lanka's civil war. Dynamics of Asymmetric Conflict, 3, 208-222. http://dx.doi.org/10 $1080 / 17467586.2010 .531031$

Jayawickreme, N., Jayawickreme, E., Goonasekera, M. A., \& Foa, E. B. (2009). Distress, wellbeing and war: Qualitative analyses of civilian interviews from north eastern Sri Lanka. Intervention, 7, 204-222. http://dx.doi.org/10.1097/WTF.0b013e328334636f

Johnson, H., \& Thompson, A. (2008). The development and maintenance of post-traumatic stress disorder (PTSD) in civilian adult survivors of war trauma and torture: A review. Clinical Psychology Review, 28, 36-47. http://dx.doi.org/10.1016/j.cpr.2007.01.017

Juster, R. P., McEwen, B. S., \& Lupien, S. J. (2010). Allostatic load biomarkers of chronic stress and impact on health and cognition. Neuroscience and Biobehavioral Reviews, 35, 2-16. http://dx.doi.org/10 .1016/j.neubiorev.2009.10.002

Kottegoda, S., Samuel, K., \& Emmanuel, S. (2008). Reproductive health concerns in six conflict-affected areas of Sri Lanka. Reproductive Health Matters, 16, 75-82. http://dx.doi.org/10.1016/S0968-8080(08)31359-7

Kumar, S., \& Willman, A. (2016). Healing invisible wounds and rebuilding livelihoods: Emerging lessons for combining livelihood and psychoso- 
cial support in fragile and conflict-affected settings. Journal of Public Health Policy, 37, 32-50. http://dx.doi.org/10.1057/s41271-016-0009-0

Lambert, J. E., Witting, A. B., Anderson, S., Ponnamperuma, L., \& Wickrama, T. (2017). Posttraumatic cognitions and depressive symptoms in war and disaster affected widows in Sri Lanka: The Role of community support. Contemporary Family Therapy. Advance online publication. http://dx.doi.org/10.1007/s10591-017-9441-y

Leaning, J., \& Guha-Sapir, D. (2013). Natural disasters, armed conflict, and public health. The New England Journal of Medicine, 369, 18361842. http://dx.doi.org/10.1056/NEJMra1109877

Long, D. A., \& Perkins, D. D. (2003). Confirmatory factor analysis of the sense of community index and development of a brief SCI. Journal of Community Psychology, 31, 279-296. http://dx.doi.org/10.1002/jcop .10046

López-Martínez, A. E., Serrano-Ibáñez, E. R., Ruiz-Párraga, G. T., GómezPérez, L., Ramírez-Maestre, C., \& Esteve, R. (2016). Physical health consequences of interpersonal trauma: A systematic review of the role of psychological variables. Trauma, Violence \& Abuse. http://dx.doi.org/ 10.1177/1524838016659488

McLean, C. P., Yeh, R., Rosenfield, D., \& Foa, E. B. (2015). Changes in negative cognitions mediate PTSD symptom reductions during clientcentered therapy and prolonged exposure for adolescents. Behaviour Research and Therapy, 68, 64-69. http://dx.doi.org/10.1016/j.brat.2015 .03 .008

Miller, K. E., \& Rasmussen, A. (2010). War exposure, daily stressors, and mental health in conflict and post-conflict settings: Bridging the divide between trauma-focused and psychosocial frameworks. Social Science \& Medicine, 70, 7-16. http://dx.doi.org/10.1016/j.socscimed.2009.09 .029

Miller, K. E., \& Rasmussen, A. (2014). War experiences, daily stressors and mental health five years on: Elaborations and future directions, 12, 33-42. http://dx.doi.org/10.1097/WTF.0000000000000066

Miller, K. E., \& Rasmussen, A. (2017). The mental health of civilians displaced by armed conflict: An ecological model of refugee distress. Epidemiology and Psychiatric Sciences, 26, 129-138. http://dx.doi.org/ 10.1017/S2045796016000172

Mollica, R. F., Caspi-Yavin, Y., Bollini, P., Truong, T., Tor, S., \& Lavelle, J. (1992). The Harvard Trauma Questionnaire: Validating a crosscultural instrument for measuring torture, trauma, and posttraumatic stress disorder in Indochinese refugees. Journal of Nervous and Mental Disease, 180, 111-116. http://dx.doi.org/10.1097/00005053-199 202000-00008

Murray, C. J., King, G., Lopez, A. D., Tomijima, N., \& Krug, E. G. (2002). Armed conflict as a public health problem. BMJ, 324, 346-349. http:// dx.doi.org/10.1136/bmj.324.7333.346

Muthén, L. K., \& Muthén, B. O. (1998-2017). Mplus user's guide (8th ed.). Los Angeles, CA: Author.

Nagai, M., Abraham, S., Okamoto, M., Kita, E., \& Aoyama, A. (2007). Reconstruction of health service systems in the post-conflict Northern Province in Sri Lanka. Health Policy, 83, 84-93. http://dx.doi.org/10 .1016/j.healthpol.2006.12.001

Nishikiori, N., Abe, T., Costa, D. G., Dharmaratne, S. D., Kunii, O., \& Moji, K. (2006). Who died as a result of the tsunami? Risk factors of mortality among internally displaced persons in Sri Lanka: A retrospective cohort analysis. BMC Public Health, 6, 73. http://dx.doi.org/10 $.1186 / 1471-2458-6-73$

Parent, M. C. (2013). Handling item-level missing data: Simpler is just as good. The Counseling Psychologist, 41, 568-600. http://dx.doi.org/10 $.1177 / 0011000012445176$

Perkins, D. D., Florin, P., Rich, R. C., Wandersman, A., \& Chavis, D. M. (1990). Participation and the social and physical environment of residential blocks: Crime and community context. American Journal of
Community Psychology, 18, 83-115. http://dx.doi.org/10.1007/BF00 922690

Rajasingham-Senanayake, D. (2004). Between reality and representation Women's agency in war and post-conflict Sri Lanka. Cultural Dynamics, 16, 141-168. http://dx.doi.org/10.1177/0921374004047741

Reilley, B., Simpson, I., Ford, N., \& DuBois, M. (2002). Conflict in Sri Lanka: Sri Lanka's health service is a casualty of 20 years of war. $B M J$, 324, 361. Retrieved from https://www.ncbi.nlm.nih.gov/pmc/articles/ PMC1122281/

Roberts, B., Patel, P., \& McKee, M. (2012). Noncommunicable diseases and post-conflict countries. Bulletin of the World Health Organization, 90, 2-2A. http://dx.doi.org/10.2471/BLT.11.098863

Sajanthan, K., Rasnayake, S., Kamalrathne, T., Chamikara, M. A. P., \& Gnanaratne, A. K. A. S. (2014). Vulnerability of war-widows in the post-war development scenario: A case study of war-torn Kandawalai Divisional Secretariat Division of the Kilinochchi District in Sri Lanka Proceedings of the Peradeniya University International Research Sessions, 18, 666. Retrieved from http://www.pdn.ac.lk/ipurse/2014/ proceeding_book/SH/666.pdf

Schumm, J. A., Dickstein, B. D., Walter, K. H., Owens, G. P., \& Chard, K. M. (2015). Changes in posttraumatic cognitions predict changes in posttraumatic stress disorder symptoms during cognitive processing therapy. Journal of Consulting and Clinical Psychology, 83, 1161-1166. http://dx.doi.org/10.1037/ccp0000040

Silva, K. T. (2012). Demographic impact of the war, changes in sex ratio and their possible effects on vulnerability and psychosocial stress in civilian populations in Northeast Sri Lanka. In D. Herath \& K. T. Silva (Eds.), Healing the wounds: Rebuilding Sri Lanka after the war (pp. 33-57). Colombo, Sri Lanka: International Center for Ethnic Studies.

Silva, K. T., Sivakanthan, S., \& Wickramasinghe, W. M. K. B. (2012). Report on community consultations on underlying causes of poverty in selected conflict-affected areas in Sri Lanka. Colombo, Sri Lanka: CARE.

Simetka, O., Reilley, B., Joseph, M., Collie, M., \& Leidinger, J. (2002). Obstetrics during civil war: Six months on a maternity ward in Mallavi, northern Sri Lanka. Medicine, Conflict, and Survival, 18, 258-270. http://dx.doi.org/10.1080/13623690208409634

Siriwardhana, C., Adikari, A., Pannala, G., Siribaddana, S., Abas, M., Sumathipala, A., \& Stewart, R. (2013). Prolonged internal displacement and common mental disorders in Sri Lanka: The COMRAID study. PLoS ONE, 8, e64742. http://dx.doi.org/10.1371/journal.pone.0064742

Siriwardhana, C., \& Wickramage, K. (2014). Conflict, forced displacement and health in Sri Lanka: A review of the research landscape. Conflict and Health, 8, 22. http://dx.doi.org/10.1186/1752-1505-8-22

Somasundaram, D. (2007). Collective trauma in northern Sri Lanka: A qualitative psychosocial-ecological study. International Journal of Mental Health Systems, 1, 5. http://dx.doi.org/10.1186/1752-4458-1-5

Tribe, R., \& De Silva, P. (1999). Psychological intervention with displaced widows in Sri Lanka. International Review of Psychiatry, 11, 184-190. http://dx.doi.org/10.1080/09540269974366

United Nations. (2011). Report of the secretary-general's panel of experts on accountability in Sri Lanka. Retrieved from www.un.org/News/dh/ infocus/Sri_Lanka/POE_Report_Full.pdf

Witting, A. B., Lambert, J., \& Wickrama, T. (2016). War and disaster in Sri Lanka: Implications for widows' family adjustment and perception of self-efficacy in caring for one's family. International Journal of Psychology. Advance online publication. http://dx.doi.org/10.1002/ijop .12407

Received October 16, 2017

Revision received December 4, 2017 Accepted December 5, 2017 